\title{
Not All Antidepressants Are Created Equal: Differential Effects of Monoamine Uptake Inhibitors on Effort-Related Choice Behavior
}

\author{
Samantha E Yohn', Samantha L Collins', Hector M Contreras-Mora', Emily L Errante', Margaret A Rowland', \\ Merce Correa ${ }^{2}$ and John D Salamone*,I \\ 'Department of Psychology, University of Connecticut, Storrs, CT, USA; 'Àrea de Psicobiologia, Campus de Riu Sec, Universitat Jaume I, \\ Castelló, Spain
}

\begin{abstract}
Motivated behavior can be characterized by behavioral activation and high work output. Moreover, people with depression and other disorders show effort-related motivational symptoms, such as anergia, psychomotor retardation, and fatigue. Effort-based decision making is studied using tasks offering choices between high effort options leading to highly valued reinforcers vs low effort/low reward options, and such tasks could be useful as animal models of motivational symptoms. In the present studies the effort-related effects of the vesicular monoamine transport (VMAT-2) inhibitor tetrabenazine (TBZ) were investigated. TBZ blocks vesicular storage and also produces depressive symptoms in humans. Moreover, TBZ alters effort-based choice in rats, biasing animals toward low effort alternatives. The present studies investigated the ability of acute administration of various monoamine uptake inhibitors to reverse the effects of TBZ. Effortrelated effects of TBZ were attenuated by the catecholamine uptake inhibitor and antidepressant bupropion, and this effect of bupropion was reversed by either $D_{1}$ or $D_{2}$ family antagonism. The effort-related effects of TBZ were also attenuated by the selective dopamine uptake blocker GBR I2909. The 5-HT uptake inhibitor fluoxetine and the norepinephrine uptake inhibitor desipramine failed to reverse the effects of TBZ, and higher doses of these drugs, given alone or in combination with TBZ, led to further behavioral impairments. These results indicate that drugs acting on dopamine transmission are relatively effective at reversing the effort-related effects of TBZ, and are consistent with the hypothesis that drugs that enhance dopamine transmission may be effective at treating effort-related psychiatric symptoms in humans.
\end{abstract}

Neuropsychopharmacology (2016) 4I, 686-694; doi:I 0.1038/npp.2015.I88; published online 28 October 2015

\section{INTRODUCTION}

Processes involved in activational aspects of motivation promote the instigation and maintenance of behavior, increase energy expenditure, and facilitate the exertion of effort to overcome obstacles that separate organisms from significant stimuli (Salamone and Correa, 2002, 2012; Yohn et al, 2015). Motivational dysfunctions related to behavioral activation are probably the most common psychiatric symptoms in general medicine (Demyttenaere et al, 2005); symptoms such as anergia, fatigue, psychomotor retardation, or apathy are frequently observed in people with depression, Parkinsonism, and other disorders (Demyttenaere et al, 2005; Fava et al, 2014). Guillion and Rush (1998) conducted a factor analytic study of depressed patients and identified a 'lack of energy' factor (ie, problems with energy/fatigability,

* Correspondence: Dr JD Salamone, Department of Psychology, University of Connecticut, 406 Babbidge Road, Storrs, CT 0626II020, USA, Tel: + I 860486 4302, Fax: + I 860486 2760,

E-mail: john.salamone@uconn.edu

Received 26 April 2015; revised 2I May 20I5; accepted 2I May 20 I5; accepted article preview online 24 June 2015 psychomotor retardation, inability to work), the factor that loaded most strongly onto a second-order general depression factor. Many people with major depression have deficits in reward seeking, exertion of effort, and effort-related decision making that are over and above any problems they may have with experiencing pleasure (Treadway and Zald, 2011; Pizzagalli, 2014). Motivational symptoms are very disabling, and the severity of effort-related symptoms in people with depression is related to problems with social function, employment, and treatment response (Tylee et al, 1999; Stahl, 2002). Many common antidepressants, including 5-HT transport (SERT) inhibitors like fluoxetine, are relatively ineffective for treating motivational dysfunction, and can induce or exacerbate these symptoms (Katz et al, 2004; Nutt et al, 2007; Padala et al, 2012; Stenman and Lilja, 2013; Fava et al, 2014; Rothschild et al, 2014).

For these reasons, it is critical to evaluate effort-related dysfunctions in animal models. Effort-based decision making is studied using tasks that offer choices between high effort instrumental actions leading to more highly valued reinforcers $v s$ low effort options leading to less valued reinforcers. In rodents, a variety of tasks have been used to assess 
effort-related decision making, including operant tasks that offer animals choices between lever pressing for a more preferred food on ratio schedules $v s$ simply approaching and consuming a less preferred reinforcer (Salamone et al, 2002, 2007; Schweimer et al, 2005; Randall et al, 2012), effort discounting (Floresco et al, 2008; Hosking et al, 2015), and a T-maze barrier climbing task (Mott et al, 2009; Mai et al, 2012; Yohn et al, 2015). Accumbens dopamine (DA) is involved in regulating energy expenditure, behavioral activation, vigor, and exertion of physical effort in motivated behavior (Salamone and Correa, 2002, 2012; Robbins and Everitt, 2007; Mai et al, 2012; McGinty et al, 2013). Across multiple paradigms, low doses of DA antagonists and accumbens DA depletions reduce the tendency to work for high reward options and increase selection of low reward choices (Salamone and Correa, 2002, 2012; Salamone et al, 2003, 2007; Floresco et al, 2008; Mai et al, 2012; Randall et al, 2012; Hosking et al, 2015). Recent studies have shown that reduced selection of high-effort alternatives in rodents is induced by manipulations associated with depression, including stress (Shafiei et al, 2012), proinflammatory cytokine administration (Nunes et al, 2014), and injections of the vesicular monoamine transporter-type 2 (VMAT-2) inhibitor tetrabenazine (TBZ; Nunes et al, 2013; Randall et al, 2014; Yohn et al, 2015). TBZ induces depressive symptoms including fatigue in humans (Frank, 2010), and recent studies show that this drug shifts choice behavior from high effort to low effort options at doses that do not impair intake of or preference for solid foods or sucrose, hedonic reactivity to sucrose, reference memory, or discrimination of reward magnitude (Nunes et al, 2013; Randall et al, 2014; Pardo et al, 2015; Yohn et al, 2015). These results from animal studies are consistent with clinical data showing that patients with major depression show reduced selection of high effort alternatives in tests of effort-based decision making (Treadway et al, 2012).

Bupropion, a catecholamine reuptake blocker that elevates extracellular DA and norepinephrine (NE; Hudson et al, 2012; Randall et al, 2015), has been shown to reverse the effort-related effects of TBZ (Nunes et al, 2013; Randall et al, 2014; Yohn et al, 2015). However, it is not clear which catecholamine mediates this action, and it is important to study monoamine uptake inhibitors with different mechanisms of action. In the present work, the first experiment investigated the ability of selective $\mathrm{DA} \mathrm{D}_{1}$ or $\mathrm{D}_{2}$ family antagonists to block the reversal of TBZ-induced effects by bupropion. Additional studies assessed the ability of the DA transporter (DAT) inhibitor GBR12909, the NE transport (NET) inhibitor desipramine, and the SERT inhibitor fluoxetine to attenuate TBZ-induced shifts in choice behavior using the fixed ratio (FR5)/chow-feeding choice task, a widely used task for assessing effort-based choice behavior (Salamone and Correa, 2002; Salamone et al, 2003; Nunes et al, 2013). Because of the literature implicating accumbens DA in effort-related process (Salamone and Correa, 2002, 2012; Salamone et al, 2003, 2007; Nunes et al, 2013), it was hypothesized that DA antagonism would block the ability of bupropion to reverse TBZ-induced effects, and that the actions of TBZ would be successfully attenuated by GBR12909, but not by fluoxetine or desipramine.

\section{MATERIALS AND METHODS}

\section{Animals}

Adult male, drug-naive, Sprague-Dawley rats $(N=37$; Harlan Sprague-Dawley, Indianapolis, IN) were housed in a colony maintained at $23^{\circ} \mathrm{C}$ with 12 -h light/dark cycles (lights on at $0700 \mathrm{~h}$ ). They weighed $300-350 \mathrm{~g}$ at the beginning of the study and were food restricted to $85 \%$ of their free-feeding body weight for initial training. Rats were fed weighed amounts of supplemental chow to maintain the food restriction, and were allowed modest growth over the course of the experiment; ad libitum water was available in their home cages. Animal protocols were approved by the University of Connecticut institutional animal care and use committee and followed NIH guidelines.

\section{Behavioral Procedures}

Concurrent FR5/chow-choice procedure. Behavioral sessions were conducted in operant conditioning chambers $(28 \times 23 \times 23 \mathrm{~cm}$, Med Associates, Georgia, VT) during the light period. Rats were initially trained to lever press on a continuous reinforcement schedule (30 min sessions, during 5 days) to obtain $45 \mathrm{mg}$ pellets, (Bioserve, Frenchtown, NJ), and then were shifted to the FR5 schedule ( 30 min sessions, 5 days/week) and trained for several additional weeks until reaching baseline targets for number of lever presses (ie, consistent responding $\geqslant 1200$ lever presses) for at least 1 week before being introduced to the concurrent FR5/chowfeeding choice procedure. In this task, weighed amounts of laboratory chow (Laboratory Diet, 5P00 Prolab RHM 3000, Purina Mills, St Louis, MO; typically 20-25 g, 4-5 large pieces) were concurrently available in the chamber during the 30 min FR5 session. At the end of the session, rats were immediately removed from the chambers, lever pressing was recorded, and amount of chow consumed was determined by weighing the remaining food and spillage.

\section{Pharmacological Agents and Dose Selection}

The DA $D_{1}$ receptor antagonist SCH 39166 (ecopipam (ECO); (6aS-trans)-11-chloro-6,6a,7,8,9,13b-hexahydro-7methyl-5H-benzo[d] naphtha[2,1-b]azepin-12-ol hydrobromide) was obtained from Tocris (Ellisville, MO). Ecopipam was dissolved in $0.9 \%$ saline also used as the vehicle control. The DA $\mathrm{D}_{2}$ antagonist haloperidol (Sigma Chemical, St Louis, MO) was dissolved in a $0.3 \%$ tartaric acid solution $(\mathrm{pH}=4.0)$; this $0.3 \%$ tartaric acid solution was also used as the vehicle control for the haloperidol injections. TBZ (9,10-dimethoxy-3-(2-methylpropyl)-1,3,4,6,7, 11b hexahydrobenzo[a]quinolizin-2-one), the VMAT-2 inhibitor, was purchased from Tocris. TBZ was dissolved in a vehicle solution of $0.9 \%$ saline $(80 \%)$ and dimethyl sulfoxide (DMSO; 20\%). Next, $1 \mathrm{~N} \mathrm{HCl} / \mathrm{ml}$ volume was added to adjust the $\mathrm{pH}$ and get the drug completely into solution. The final $\mathrm{pH}$ of the TBZ solution was 3.5-4.0. The 20\% DMSO/ saline vehicle solution was administered as the vehicle control. The DAT inhibitor GBR12909 (1-[2-[bis(4-fluorophenyl)methoxy] ethyl]-4-(3-phenylpropyl)-piperazine, dihydrochloride) was obtained from Cayman Chemical (Ann Arbor, MI). GBR12909 was used because it is $>100$-fold lower in affinity for SERT and NET (Anderson, 1989). 
Bupropion was dissolved in $0.9 \%$ saline. Desipramine was purchased from Sigma Aldrich (Saint Louis, MO) and was dissolved in a vehicle solution of $0.9 \%$ saline, with light heat added using a hot plate in order to fully dissolve the drug in solution. The SERT inhibitor fluoxetine $(( \pm)-N$-Methyl- $\gamma$ [4- (trifluoromethyl)phenoxy] benzenepropanamine hydrochloride was purchased from Sigma-Aldrich, and dissolved in $0.9 \%$ saline.

The doses of $0.75 \mathrm{mg} / \mathrm{kg}$ TBZ and $15.0 \mathrm{mg} / \mathrm{kg}$ bupropion were based on previous work from our laboratory (Nunes et al, 2013a; Randall et al, 2014; Yohn et al, 2015). The subthreshold doses of $0.05 \mathrm{mg} / \mathrm{kg}$ ECO and HAL were based on previous research (Sink et al, 2008). The doses of fluoxetine and desipramine were based on studies involving traditional rodent antidepressant screening tests (Armario et al, 1988; Jang et al, 2009), and recent studies showing that fluoxetine suppresses locomotion and induces tremor in TBZ-treated rats (Podurgiel et al, 2015). The doses of GBR were based upon rodent runway studies (Esumi et al, 2013).

\section{Experimental Procedures}

Different groups of rats, trained as described above, were used for each experiment. All experiments used a withingroups design in which each rat received all i.p. doses of drug or vehicle treatments in their particular experiment in a randomly varied order (one treatment per week; no treatment sequence repeated across different animals in the experiment). Immediately after the $30 \mathrm{~min}$ session, rats were removed from the chambers, total lever presses were recorded, and chow consumed was calculated. Baseline (nondrug) training sessions were conducted 4 days per week.

Experiment 1: Ability of the $\mathrm{DA} \mathrm{D}_{1}$ receptor antagonist ecopipam and the $\mathrm{DA} \mathrm{D}_{2}$ receptor antagonist haloperidol to attenuate the effects of bupropion on TBZ-induced shifts in behavior on the concurrent FR5/chow-feeding procedure.

Trained rats $(n=7)$ received injections of vehicle or the following drug treatments before testing (injection times before testing are listed): TBZ (90 $\mathrm{min}$ before testing), bupropion (30 $\mathrm{min})$, haloperidol (50 $\mathrm{min})$, and ecopipam (20 min). Timing of the vehicle injections corresponded with the timing of the respective drug treatments listed above. All rats received three injections, and the following seven combined treatments were given: TBZ vehicle+bupropion vehicle+ecopipam or haloperidol vehicle (50 or $20 \mathrm{~min}$ before testing, randomized across animals); TBZ vehicle+bupropion vehicle $+0.05 \mathrm{mg} / \mathrm{kg}$ ecopipam; TBZ vehicle+bupropion vehicle +0.05 haloperidol; $0.75 \mathrm{mg} / \mathrm{kg} \quad \mathrm{TBZ}+$ bupropion vehicle+ecopipam or haloperidol vehicle; $0.75 \mathrm{mg} / \mathrm{kg}$ $\mathrm{TBZ}+15.0 \mathrm{mg} / \mathrm{kg}$ bupropion+ecopipam or haloperidol vehicle; $\quad 0.75 \mathrm{mg} / \mathrm{kg} \quad \mathrm{TBZ}+15.0 \mathrm{mg} / \mathrm{kg}$ bupropion $+0.05 \mathrm{mg} / \mathrm{kg}$ ecopipam; and $0.75 \mathrm{mg} / \mathrm{kg} \mathrm{TBZ}+15.0 \mathrm{mg} / \mathrm{kg}$ bupropion $+0.05 \mathrm{mg} / \mathrm{kg}$ haloperidol.

Experiment 2: Ability of the DAT inhibitor, GBR12909, to attenuate TBZ-induced shifts in behavior on the concurrent FR5/chow-feeding procedure.

Trained rats $(n=8)$ received the following combined treatments of TBZ or TBZ vehicle 90 min before testing plus GBR12909 or its respective vehicle $20 \mathrm{~min}$ before testing: TBZ vehicle+GBR12909 vehicle; $0.75 \mathrm{mg} / \mathrm{kg}$ TBZ+GBR12909 vehicle; $0.75 \mathrm{mg} / \mathrm{kg}$ TBZ+1.25 mg/kg GBR12909; $0.75 \mathrm{mg} / \mathrm{kg}$
TBZ+2.5 mg/kg GBR12909; or $0.75 \mathrm{mg} / \mathrm{kg}$ TBZ+5.0 mg/kg GBR12909.

Experiment 3: Ability of the NET inhibitor desipramine to attenuate TBZ-induced shifts in behavior on the concurrent FR5/chow-feeding procedure.

Trained rats $(n=6)$ received the following combined treatments of TBZ or TBZ vehicle 90 min before testing plus desipramine or its vehicle $45 \mathrm{~min}$ before testing: TBZ vehicle +desipramine vehicle; $0.75 \mathrm{mg} / \mathrm{kg}$ TBZ+desipramine vehicle; $0.75 \mathrm{mg} / \mathrm{kg} \mathrm{TBZ}+2.5 \mathrm{mg} / \mathrm{kg}$ desipramine; $0.75 \mathrm{mg} / \mathrm{kg} \mathrm{TBZ}$ $+5.0 \mathrm{mg} / \mathrm{kg}$ desipramine; $0.75 \mathrm{mg} / \mathrm{kg} \mathrm{TBZ}+10.0 \mathrm{mg} / \mathrm{kg}$ desipramine; and $0.75 \mathrm{mg} / \mathrm{kg} \mathrm{TBZ}+20.0 \mathrm{mg} / \mathrm{kg}$ desipramine.

Experiment 4: Ability of the SERT inhibitor fluoxetine to attenuate TBZ-induced shifts in behavior on the concurrent FR5/chow-feeding procedure.

Trained rats $(n=9)$ received the following combined drug treatments (simultaneous i.p. injections) of vehicle, TBZ, or fluoxetine $90 \mathrm{~min}$ before testing: TBZ vehicle+fluoxetine vehicle; $0.75 \mathrm{mg} / \mathrm{kg}$ TBZ+fluoxetine vehicle; $0.75 \mathrm{mg} / \mathrm{kg} \mathrm{TBZ}$ $+2.5 \mathrm{mg} / \mathrm{kg}$ fluoxetine; $0.75 \mathrm{mg} / \mathrm{kg} \mathrm{TBZ}+5.0 \mathrm{mg} / \mathrm{kg}$ fluoxetine; and $0.75 \mathrm{mg} / \mathrm{kg} \mathrm{TBZ}+10.0 \mathrm{mg} / \mathrm{kg}$ fluoxetine.

Experiment 5: Effects of bupropion, GBR12909, desipramine, and fluoxetine alone on performance of rats tested on the concurrent FR5/chow-feeding procedure.

Trained rats $(n=7)$ received the following treatments at the listed times before treatment: vehicle $(90,45$, or $20 \mathrm{~min}$, times randomized across animals); $15.0 \mathrm{mg} / \mathrm{kg}$ bupropion (45 min); GBR12909 (20 min); fluoxetine (90 min); and desipramine (45 min).

\section{Statistical Analyses}

Total number of lever presses and gram quantity of chow intake from the $30 \mathrm{~min}$ session were analyzed using repeated measures ANOVA. A computerized statistical program (SPSS 21.0 for Windows) was used to perform all analyses. When there was a significant ANOVA, nonorthogonal planned comparisons using the overall error term were employed to assess the differences between each treatment and the control condition. The number of comparisons was restricted to the number of treatments minus one (Keppel, 1991).

\section{RESULTS}

Experiment 1: Ability of the DA $\mathrm{D}_{1}$ receptor antagonist ecopipam and the $\mathrm{DA} \mathrm{D}_{2}$ receptor antagonist haloperidol to attenuate the effects of bupropion on tetrabenazine-induced shifts in behavior on the concurrent FR5/chow-feeding procedure.

Administration of either the $D_{1}$ antagonist ecopipam or the $\mathrm{D}_{2}$ antagonist haloperidol substantially attenuated the effects of bupropion in tetrabenazine-treated rats (Table 1). There was an overall significant effect of drug treatment on lever presses $(\mathrm{F}(4,24)=106.183, P<0.001)$. Tetrabenazine significantly lowered lever presses relative to vehicle control (planned comparison, $P<0.01$ ). Administration of $15.0 \mathrm{mg} / \mathrm{kg}$ bupropion significantly increased lever pressing in TBZtreated rats $(P<0.01)$. Coadministration of either $0.05 \mathrm{mg} / \mathrm{kg}$ ecopipam or $0.05 \mathrm{mg} / \mathrm{kg}$ haloperidol significantly blocked the effects of bupropion in TBZ-treated rats $(P<0.01)$. However, these doses of ecopipam or haloperidol had no effect on 
Table I Ability of the DA D, Receptor Antagonist Ecopipam and the DA $D_{2}$ Receptor Antagonist Haloperidol to Attenuate the Effects of Bupropion on TBZ-Induced Shifts in Behavior

\begin{tabular}{lcc}
\hline Condition & $\begin{array}{c}\text { Lever Presses } \\
( \pm \text { SEM) }\end{array}$ & $\begin{array}{c}\text { Chow Consumption } \\
( \pm \text { SEM) }\end{array}$ \\
\hline$V N N$ & $1719.9( \pm 84.5)$ & $1.6( \pm 0.4)$ \\
$H / N N$ & $1217.1( \pm 228.5)$ & $3.5( \pm 1.1)$ \\
$E N N N$ & $1323.7( \pm 189.3)$ & $3.7( \pm 0.7)$ \\
$V / T / N$ & $225.0( \pm 75.9) \#$ & $6.3( \pm 0.6) \#$ \\
$V / T / B$ & $1264.6( \pm 84.4)^{* *}$ & $1.3( \pm 0.3)^{* * *}$ \\
$H / T / B$ & $65.9( \pm 19.6)^{\wedge}$ & $7.0( \pm 0.6)^{\wedge}$ \\
$E / T / B$ & $255.3( \pm 71.8)^{\wedge}$ & $5.2( \pm 0.6)^{\wedge}$ \\
\hline$A b b r$ &
\end{tabular}

Abbreviations: B, $15.0 \mathrm{mg} / \mathrm{kg}$ bupropion; E, $0.05 \mathrm{mg} / \mathrm{kg}$ ecopipam; H, $0.05 \mathrm{mg} / \mathrm{kg}$ haloperidol; $T, 0.75 \mathrm{mg} / \mathrm{kg}$ tetrabenazine; $\mathrm{V}$, vehicle.

${ }^{\#} P<0.01, V / T / N$ different from $V / N / N$, planned comparison; ${ }^{*} * P<0.01, V / T / B$ different from $V / T / N$ (ie, bupropion reversal effect); $\wedge^{\wedge}<0.05, H / T / B$ and $E / T / B$ different from $V / T / B$, planned comparisons (ie, haloperidol and ecopipam attenuation of bupropion reversal effect).

responding when administered alone. The overall treatment effect for chow consumption was also statistically significant $(\mathrm{F}(4,24)=30.908, P<0.001)$. Chow intake was significantly increased by TBZ relative to vehicle $(P<0.01)$. Planned comparisons showed that chow intake was significantly reduced in TBZ-treated rats by coadministration of bupropion $(P<0.01)$. The shift in choice behavior induced by bupropion in TBZ-treated animals was significantly blocked by administration of either $0.05 \mathrm{mg} / \mathrm{kg}$ ecopipam or haloperidol $(P<0.01)$. Administration of $0.05 \mathrm{mg} / \mathrm{kg}$ ecopipam or haloperidol alone did not affect chow consumption.

Experiment 2: Ability of the DAT inhibitor GBR12909 to attenuate TBZ-induced shifts in behavior on the concurrent FR5/chow-feeding procedure.

GBR12909 attenuated the effects of TBZ on the concurrent lever pressing/chow-feeding task. The overall treatment effect for lever pressing was statistically significant $(\mathrm{F}(4$, $28)=29.111, \quad P<0.001$; Figure 1). Planned comparisons revealed that TBZ significantly decreased lever pressing compared with the vehicle-vehicle treatment $(P<0.01)$. GBR12909 significantly reversed the suppression of lever pressing induced by TBZ, with 2.5 and $5.0 \mathrm{mg} / \mathrm{kg}$ GBR12909 plus TBZ being statistically different from TBZ-vehicle $(P<0.05)$. The overall treatment effect for chow consumption was also statistically significant $(\mathrm{F}(4,28)=15.508$, $P<0.001)$. Planned comparisons revealed that TBZ significantly increased chow consumption in TBZ-treated rats $(P<0.01)$. Chow consumption was significantly reduced at 2.5 and $5.0 \mathrm{mg} / \mathrm{kg}$ GBR12909 plus TBZ compared with TBZ alone (planned comparisons, $P<0.05$ ).

Experiment 3: The NET inhibitor desipramine fails to attenuate TBZ-induced shifts in behavior on the concurrent FR5/chow-feeding procedure.

Repeated measures ANOVA demonstrated that there was an overall significant effect of drug treatment on lever presses $(\mathrm{F}(5,25)=19.277, P<0.001$; Figure 2$)$. TBZ significantly lowered lever pressing compared with vehicle control (planned comparisons, $P<0.01$ ). Planned comparisons also revealed that coadministration of desipramine further

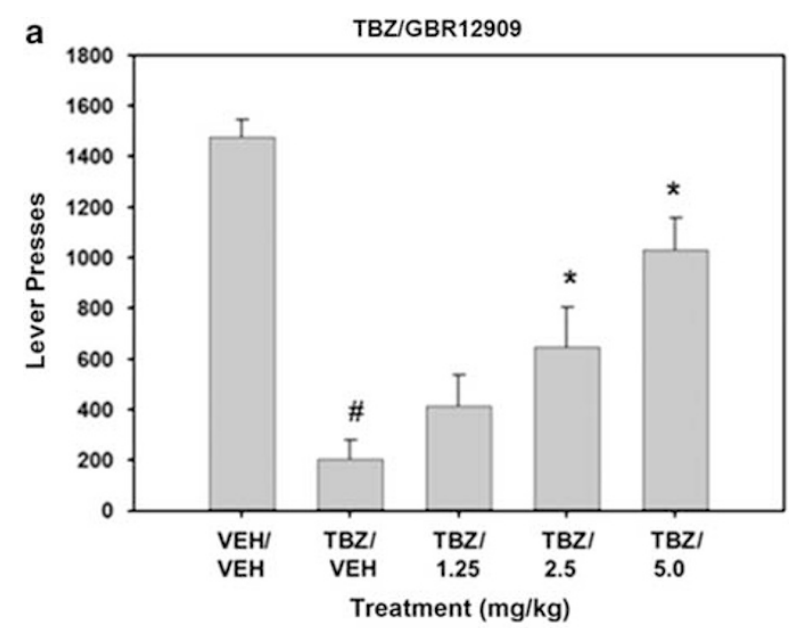

b

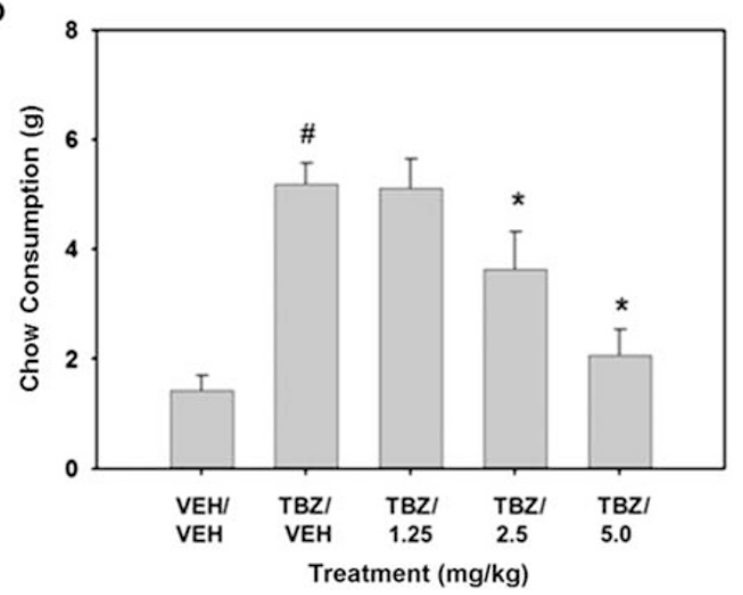

Figure I Ability of the DAT inhibitor GBRI2909 to attenuate TBZinduced shifts in effort-related choice behavior. (a) Mean ( \pm SEM) number of lever presses (FR5 schedule) during the 30 min session after treatment with vehicle or tetrabenazine and various doses of GBRI2909. (b) Mean $( \pm$ SEM) number of lab chow intake (in g) after treatment with vehicle or tetrabenazine and various doses of GBR 12909 are shown. VEH/NEH (vehicle plus vehicle), TBZNEH $(0.75 \mathrm{mg} / \mathrm{kg}$ tetrabenazine plus vehicle), TBZ/l.25 (0.75 mg/kg tetrabenazine plus $1.25 \mathrm{mg} / \mathrm{kg}$ GBR), TBZ/2.5 (0.75 mg/ $/ \mathrm{kg}$ tetrabenazine plus $2.5 \mathrm{mg} / \mathrm{kg}$ GBR), and TBZ/5.0 $(0.75 \mathrm{mg} / \mathrm{kg}$ tetrabenazine plus $5.0 \mathrm{mg} / \mathrm{kg}$ GBR). ${ }^{\#} P<0.01$, tetrabenazine/vehicle different from vehicle/vehicle, planned comparison; $* P<0.01$, tetrabenazine/GBR different from tetrabenazine/vehicle, planned comparisons.

suppressed lever pressing in TBZ-treated rats at the $20.0 \mathrm{mg} / \mathrm{kg}$ dose $(P<0.05)$. There was also a significant effect of drug treatment on chow consumption $(\mathrm{F}(5,25)=5.593$, $P<0.005)$. TBZ significantly increased chow intake compared with vehicle-treated animals $(P<0.01)$. Planned comparisons showed that coadministration of $20.0 \mathrm{mg} / \mathrm{kg}$ desipramine with TBZ significantly decreased chow intake relative to TBZ plus vehicle.

Experiment 4: The SERT inhibitor fluoxetine fails to attenuate TBZ-induced shifts in behavior on the concurrent FR5/chow-feeding procedure.

Fluoxetine did not reverse the effects of TBZ in rats tested on the FR5/chow-feeding choice test, and in fact tended to exacerbate them (Figure 3). There was an overall significant effect of drug treatment on lever pressing $(\mathrm{F}(4,32)=67.459$, 


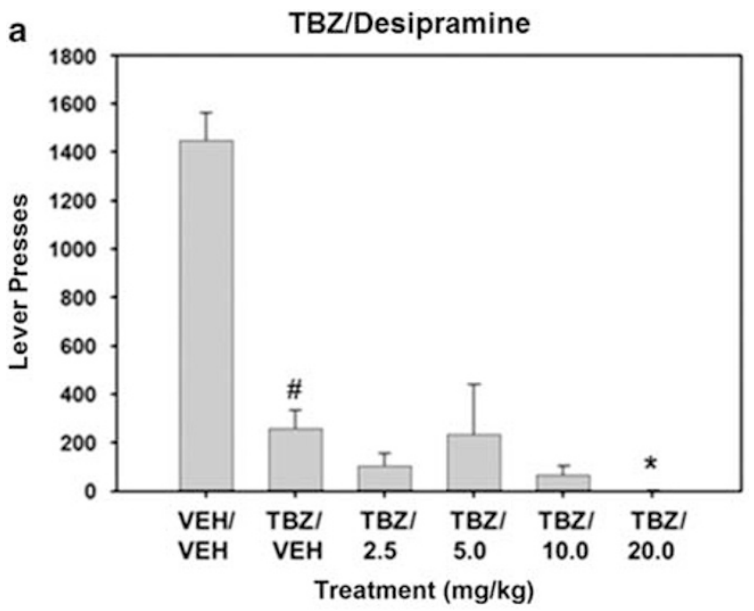

b

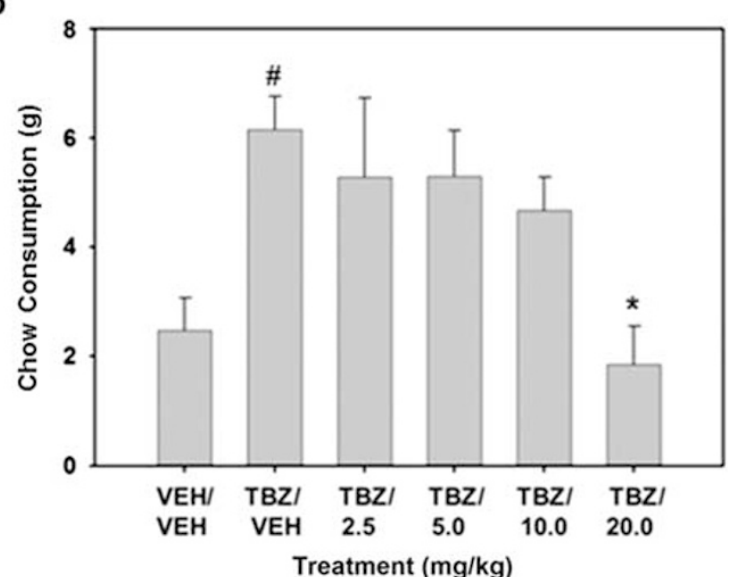

Figure 2 The NET inhibitor desipramine fails to reverse TBZ-induced shifts in effort-related choice behavior. (a) Mean ( \pm SEM) number of lever presses (FR5 schedule) during the 30 min session after treatment with vehicle or tetrabenazine and various doses of desipramine. (b) Mean $( \pm$ SEM) number of lab chow intake (in g) after treatment with vehicle or tetrabenazine and various doses of desipramine are shown. VEH/NEH (vehicle plus vehicle), TBZ/VEH (0.75 mg/ $\mathrm{kg}$ tetrabenazine plus vehicle), TBZ/2.5 $(0.75 \mathrm{mg} / \mathrm{kg}$ tetrabenazine plus $2.5 \mathrm{mg} / \mathrm{kg}$ desipramine, TBZ/5.0 ( $0.75 \mathrm{mg} / \mathrm{kg}$ tetrabenazine plus $5.0 \mathrm{mg} / \mathrm{kg}$ desipramine), TBZ/ I 0.0 (0.75 mg/kg tetrabenazine plus 10.0 despiramine), and TBZ/20.0 (0.75 mg/ $/ \mathrm{kg}$ tetrabenazine plus 20.0 desipramine). ${ }^{\#} P<0.01$, tetrabenazine/vehicle different from vehicle/vehicle, planned comparison; ${ }^{*} P<0.05$, tetrabenazine/desipramine different from tetrabenazine/vehicle, planned comparisons.

$P<0.001)$. Planned comparisons showed that TBZ significantly decreased lever pressing compared with vehiclecontrol treatment $(P<0.01)$. Planned comparisons revealed that administration of fluoxetine further suppressed lever pressing in TBZ-treated rats at doses of $2.5,5.0$, and $10.0 \mathrm{mg} / \mathrm{kg}$ $(P<0.01)$. The overall treatment effect for chow consumption was also statistically significant $(\mathrm{F}(4,32)=13.191$, $P<0.001)$. TBZ-treated animals showed significantly increased chow consumption compared with vehicle-control animals (planned comparisons, $P<0.01$ ). Chow consumption was significantly reduced by 5.0 and $10.0 \mathrm{mg} / \mathrm{kg}$ fluoxetine plus TBZ compared with TBZ alone $(P<0.01)$.

Experiment 5: Effects of bupropion, GBR12909, desipramine, and fluoxetine on performance on rats tested on the concurrent FR5/chow-feeding procedure.

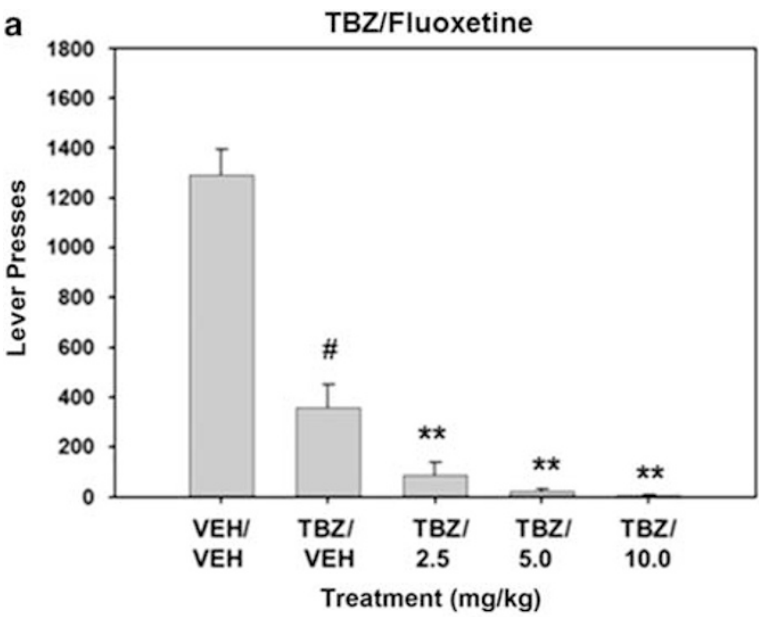

b

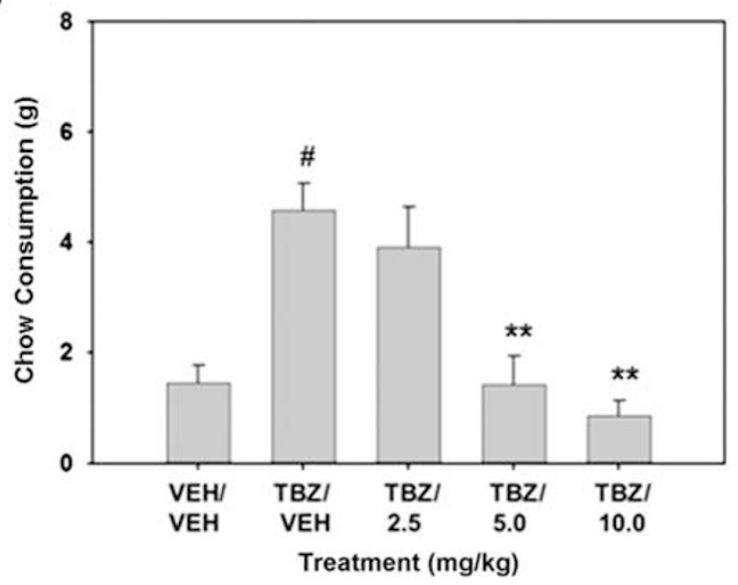

Figure 3 The SERT inhibitor fluoxetine fails to attenuate TBZ-induced shifts in behavior on the concurrent FR5/chow-feeding procedure. (a) Mean $( \pm$ SEM) number of lever presses (FR5 schedule) during the 30 min session after treatment with vehicle or tetrabenazine and various doses of fluoxetine. (b) Mean ( \pm SEM) number of lab chow intake (in g) after treatment with vehicle or tetrabenazine and various doses of fluoxetine are shown. VEH/NEH (vehicle plus vehicle), TBZNEH (0.75 mg/kg tetrabenazine plus vehicle), TBZ/2.5 (0.75 mg/kg tetrabenazine plus $2.5 \mathrm{mg} / \mathrm{kg}$ fluoxetine, TBZ/5.0 (0.75 mg/kg tetrabenazine plus $5.0 \mathrm{mg} / \mathrm{kg}$ fluoxetine), and TBZ/I0.0 (0.75 mg/kg tetrabenazine plus $10.0 \mathrm{mg} / \mathrm{kg}$ fluoxetine). ${ }^{\#} P<0.01$, tetrabenazine/vehicle different from vehicle/vehicle, planned comparison; ** $P<0.01$, tetrabenazine/fluoxetine different from tetrabenazine/vehicle, planned comparisons.

There was an overall significant effect of drug treatment on lever presses $(F(4,24)=19.584, P<0.001$; Figure 4$)$. Systemic administration of $10.0 \mathrm{mg} / \mathrm{kg}$ fluoxetine and $20.0 \mathrm{mg} / \mathrm{kg}$ desipramine significantly reduced lever pressing compared with vehicle-control conditions $(P<0.05)$. There was no significant overall effect of drug treatment on chow consumption $(\mathrm{F}(2,24)=1.564, P=0.216)$.

\section{DISCUSSION}

These experiments evaluated the ability of monoamine uptake inhibitors with varying mechanisms of action to reverse the effort-related effects of the VMAT-2 inhibitor TBZ. This work was undertaken to focus on effort-related 


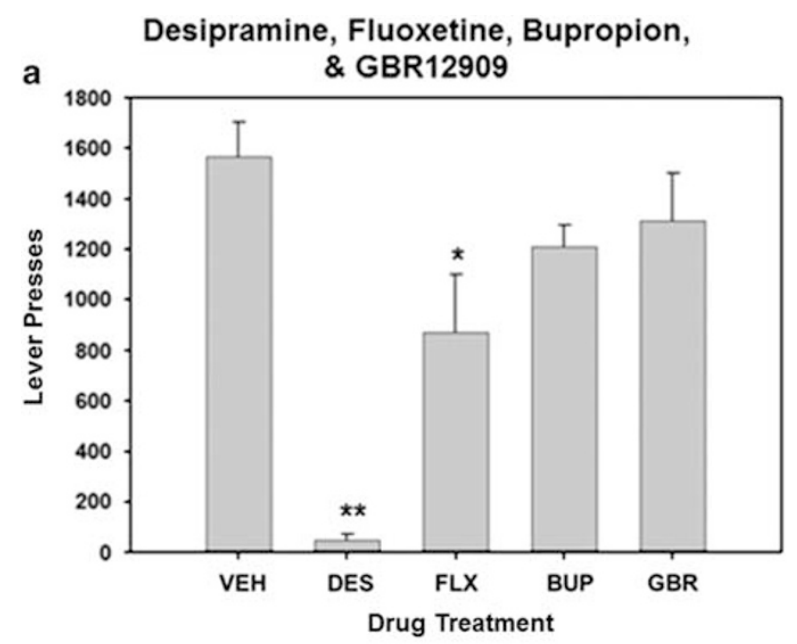

b

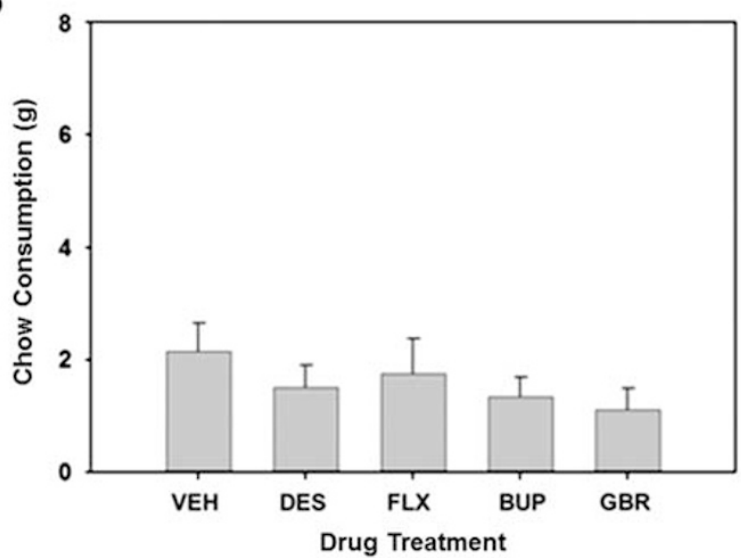

Figure 4 Effects of bupropion, GBRI2909, desipramine, and fluoxetine (administered in the absence of tetrabenazine) on performance of rats tested on the concurrent FR5/chow-choice procedure. (a) Mean ( \pm SEM) number of lever presses (FR5 schedule) during the 30 min session after treatment with vehicle or the highest doses of GBR I2909, desipramine, and fluoxetine. (b) Mean ( \pm SEM) number of lab chow intake (in g) after treatment with vehicle or the highest doses of GBR 12909, desipramine, and fluoxetine are shown. VEH (vehicle), GBR $(5.0 \mathrm{mg} / \mathrm{kg}$ GBR 12909), DES $\left(20.0 \mathrm{mg} / \mathrm{kg}\right.$ desipramine), and $\mathrm{FLX}\left(10.0 \mathrm{mg} / \mathrm{kg}\right.$ fluoxetine). ${ }^{*} P<0.05$, ** $P<0.0$ I, different from vehicle, planned comparisons.

functions that may be highly relevant for understanding some of the motivational symptoms of depression and other disorders (Treadway et al, 2012; Randall et al, 2014, 2015; Yohn et al, 2015; Nunes et al, 2013a,b). Rodent tests of effortrelated dysfunction are likely to reflect a component of depression rather than a global measure, and possibly represent models of motivational symptoms that cross multiple diagnostic categories, rather than a model of a specific disorder (Yohn et al, 2015). This approach is consistent with the NIMH Research Domain Criterion (RDoC) initiative that emphasizes specific psychiatric symptoms and their associated neural circuits rather than traditional diagnostic categories or disorders (Cuthbert and Insel, 2013).

TBZ was used as a tool for altering effort-related choice because this drug has been reported to induce depressive symptoms including fatigue in people (Frank, 2010; Chen et al, 2012), and behavioral effects in traditional rodent depression models (Tadano et al, 2000; Wang et al, 2010). Recent studies have shown that $0.75 \mathrm{mg} / \mathrm{kg}$ TBZ reduces extracellular DA in nucleus accumbens core by $~ 75 \%$ from baseline, and also alters expression of DA and cyclicAMPrelated phosphoprotein $32 \mathrm{kDa}$ (DARPP-32) in a manner consistent with a reduction of DA transmission at both $\mathrm{D}_{1}$ and $\mathrm{D}_{2}$ family receptors (Nunes et al, 2013). TBZ alters effort-related decision making across multiple tasks, and these effects were shown to be reversed by the adenosine $A_{2 A}$ antagonist MSX-3, as well as the catecholamine uptake inhibitor bupropion (Nunes et al, 2013; Randall et al, 2014, 2015; Yohn et al, 2015). Bupropion (Wellbutrin) is a widely used antidepressant; however, it was not clear in previous studies if the effort-related effects of this drug were being mediated by DA or NE. In experiment 1 , it was shown that the ability of bupropion to reverse the effects of TBZ was completely blocked by the $\mathrm{D}_{1}$ antagonist ecopipam and the $\mathrm{D}_{2}$ antagonist haloperidol at low doses of these antagonists that had no effect on their own. This pattern of effects indicates that the ability of bupropion to reverse the effortrelated effects of TBZ is dependent upon stimulation of both $D_{1}$ and $D_{2}$ family receptors. These findings are consistent with Yamada et al (2004), who reported that the antiimmobility effects of bupropion in mice tested on the forced swim test were blocked by either $\mathrm{D}_{1}$ or $\mathrm{D}_{2}$ antagonism, and with Randall et al (2015), who found that bupropion increases extracellular DA, as well as DA-related signal transduction markers (DARPP-32 expression) related to $\mathrm{D}_{1}$ and $\mathrm{D}_{2}$ signaling in nucleus accumbens. Furthermore, experiment 2 showed that the TBZ-induced shift in effortrelated choice was reversed by the selective DAT blocker GBR1209. In contrast, the effort-related effects of TBZ were not blocked by the NET blocker desipramine, consistent with recent studies showing that the NET blocker atomoxetine had no effect on physical effort discounting (Hosking et al, 2015). It is worth noting that desipramine not only tended to suppress lever pressing, but also reduced chow intake in TBZ-treated rats. It is possible that this reflects sedative effects or actions of the drug on aspects of food motivation. Taken together, these results reinforce previous findings demonstrating that DA, especially in nucleus accumbens, is a key neurotransmitter in the overall circuitry regulating effort-based decision making (Salamone and Correa, 2012).

Several clinical reports indicate that SERT inhibitors such as fluoxetine are relatively ineffective for treating psychomotor or motivational dysfunction, and can induce or exacerbate these symptoms (Katz et al, 2004; Nutt et al, 2007; Padala et al, 2012; Stenman and Lilja, 2013; Fava et al, 2014; Rothschild et al, 2014). Results from experiment 4 showed that, in contrast to bupropion and GBR12909, administration of fluoxetine was unable to reverse the effects of TBZ and, in fact, administration of fluoxetine further suppressed lever pressing. Moreover, fluoxetine administered alone in experiment 5 significantly reduced lever pressing, but did not affect chow intake. Previous studies have shown that fluoxetine or genetic deletion of SERT decreased food reinforced progressive ratio responding in mice (Sanders et al, 2007). In most clinical studies, patients prescribed SERT blockers have high prevalence rates of fatigue (Nierenberg et al, 2010), and the presence of fatigue is associated with reduced probability of achieving remission with SERT inhibitor monotherapy. An analysis of six double-blind, randomized trials of 
bupropion and SERT inhibitors by Papakostas et al (2006) showed that bupropion offered potential advantages over SERT inhibitors in the resolution of fatigue. Interestingly, patients who are more likely to respond to fluoxetine report different depressive characteristics than those who respond to bupropion; whereas bupropion responders describe their depression as more highly energy related, those who respond to fluoxetine are more likely to experience mood disorder, rumination, and anxiety (Bell et al, 2013). Demyttenaere et al (2005) suggested that the neurological basis of motivational symptoms such as fatigue is governed by specific neural circuits, and therefore the specific symptom profiles of depression need to be evaluated in the context of the drug and its neurobiological mechanism of action (see also Cooper et al, 2014). The present studies, in combination with additional clinical and preclinical reports (Salamone and Correa, 2002, 2012; Salamone et al, 2003, 2007; Treadway and Zald, 2011; Mai et al, 2012; Esumi et al, 2013; Pizzagali, 2014), indicate that compared with other monoamines, DA appears to be a key component of the specific circuitry regulating effort-related motivational dysfunctions.

In conclusion, the present studies indicate that monoamine uptake inhibitors with distinct mechanisms of action have differential effects on effort-related choice behavior. The DAT/NET inhibitor bupropion is able to reverse the effects of TBZ on effort-related choice, and this effect depends upon stimulation of DA $\mathrm{D}_{1}$ and $\mathrm{D}_{2}$ family receptors. In addition, the selective DAT inhibitor GBR12909 is also able to reverse the effort-related effects of TBZ. Based upon previous studies (Nunes et al, 2013; Randall et al, 2015), it is likely that these effects are because of actions on nucleus accumbens DA, although the role of prefrontal/anterior cingulate cortex DA cannot be discounted (Schweimer et al, 2005; Schweimer and Hauber, 2006). In contrast to the effects of the DAT inhibitors, neither the NET inhibitor desipramine nor the SERT inhibitor fluoxetine were able to reverse the effects of TBZ and, in fact, these drugs tended to reduce lever pressing output at higher doses, either alone or in combination with TBZ. Taken together, these results indicate that tests of effort-based decision making are able to differentiate between antidepressant drugs with different pharmacodynamic profiles, and the pattern of effects observed in rats is consistent with previous observations of the effects of bupropion and fluoxetine on motivational symptoms in humans (see, eg, Papakostas et al, 2006). Moreover, in so far as these results may be related specifically to depressive symptoms, they indicate that there is a dopaminergic component that is particularly critical for effort-related motivational dysfunction. Of course, this does not mean that other transmitters, such as 5-HT, are not involved in other aspects of depression (eg, mood dysfunction, rumination, anxiety, hostility; see Katz et al, 2004; Carr and Lucki, 2011; Bell et al, 2013). The present studies focused upon the ability of acute administration of monoamine uptake inhibitors to reverse the effects of TBZ that may be highly relevant in view of studies showing that drugs that block DAT can improve motivational symptoms in depressed people within a few hours after administration (Stotz et al, 1998). Nevertheless, future studies need to extend this line of work to include repeated administration, as well as tests that assess the ability of antidepressants to increase exertion of effort in otherwise untreated animals. Moreover, it will be important to translate this work to humans by assessing the effects of antidepressants using tasks of effort-related function (eg, Treadway et al, 2012).

\section{FUNDING AND DISCLOSURE}

JDS has received grants from, and done consulting work for, Pfizer, Roche, Shire, and Prexa. The authors declare no conflict of interest.

\section{ACKNOWLEDGMENTS}

We thank Aileen Haque and Myles Jones for their assistance. This research was supported by a grant to JDS from NIH/ NIMH (MH094966), and to MC from Fundació Bancaixa/U Jaume I (P1.1B2010-43). It was also supported by the University of Connecticut Research Foundation (to SEY), and the Psychology Department Undergraduate Research Grant program (to MAR and ELE). HMC-M received an NSF Bridge to the Doctorate grant.

\section{REFERENCES}

Anderson PH (1989). The dopamine inhibitor GBR 12909: selectivity and molecular mechanism of action. Eur J Pharmacol 166: 504.

Armario A, Gavaldà A, Martí O (1988). Forced swimming test in rats: effect of desipramine administration and the period of exposure to the test on struggling behavior, swimming, immobility and defecation rate. Eur J Pharmacol 158: 207-212.

Bell DS, Shipman WM, Cleves MA, Siegelman J (2013). Which drug for which patient? Is there a fluoxetine responding versus a bupropion responding personality profile? Clin Pract Epidemiol Ment Health 9: 142-147.

Carr GV, Lucki I (2011). The role of serotonin receptor subtypes in treating depression: a review of animal studies. Psychopharmacology 213: 265-287.

Chen JJ, Ondo WG, Dashtipour K, Swope DM (2012). Tetrabenazine for the treatment of hyperkinetic movement disorders: a review of the literature. Clin Ther 34: 1487-1504.

Cooper JA, Tucker VL, Papakostas GI (2014). Resolution of sleepiness and fatigue: a comparison of bupropion and selective serotonin reuptake inhibitors in subjects with major depressive disorder achieving remission at doses approved in the European Union. J Psychopharmacol 28: 118-124.

Cuthbert BN, Insel TR (2013). Toward the future of psychiatric diagnosis: the seven pillars of RDoC. BMC Med 11: 126.

Demyttenaere K, De Fruyt J, Stahl SM (2005). The many faces of fatigue in major depressive disorder. J Neuropsychopharmacol 8: 93-105.

Esumi S, Sagara H, Nakamoto A, Kawasaki Y, Gomita Y, Sendo T (2013). Effect of GBR12909 on affective behavior: distinguishing motivational behavior from antidepressant-like and addictionlike behavior using the runway model of intracranial selfstimulation. Behav Brain Res 243: 313-321.

Fava M, Ball S, Nelson JC, Sparks J, Konechnik T, Classi P et al (2014). Clinical relevance of fatigue as a residual symptom in major depressive disorder. Depress Anxiety 31: 250-257.

Floresco SB, Tse MT, Ghods-Sharifi S (2008). Dopaminergic and glutamatergic regulation of effort- and delay-based decision making. Neuropsychopharmacology 33: 1966-1979.

Frank S (2010). Tetrabenazine: the first approved drug for the treatment of chorea in US patients with Huntington disease. Neuropsychiatr Dis Treat 6: 657-665. 
Gullion CM, Rush AJ (1998). Toward a generalizable model of symptoms in major depressive disorder. Biol Psychiatry 44: 959-972.

Hosking JG, Floresco SB, Winstanley CA (2015). Dopamine antagonism decreases willingness to expend physical, but not cognitive, effort: a comparison of two rodent cost/benefit decisionmaking tasks. Neuropsychopharmacology 40: 1005-1015.

Hudson AL, Lalies MD, Silverstone P (2012). Venlafaxine enhances the effect of bupropion on extracellular dopamine in rat frontal cortex. Canadian J Physiol Pharmacol 90: 803-809.

Jang DP, Lee SH, Park CW, Lee SY, Kim YB, Cho ZH (2009). Effects of fluoxetine on the rat brain in the forced swimming test: a [F-18]FDG micro-PET imaging study. Neurosci Lett 451: 60-64.

Katz MM, Tekell JL, Bowden CL, Brannan S, Houston JP, Berman N et al (2004). Onset and early behavioral effects of pharmacologically different antidepressants and placebo in depression. Neuropsychopharmacology 29: 566-579.

Keppel G (1991). Design and Analysis: A Researcher's Handbook. Prentice-Hall: Upper Saddle River, NJ.

Mai B, Sommer S, Hauber W (2012). Motivational states influence effort-based decision making in rats: the role of dopamine in the nucleus accumbens. Cogn Affect Behav Neurosci 12: 74-84.

McGinty VB, Lardeux S, Taha SA, Kim JJ, Nicola SM (2013). Invigoration of reward seeking by cue and proximity encoding in the nucleus accumbens. Neuron 78: 910-922.

Mott AM, Nunes EJ, Collins LE, Port RG, Sink KS, Hockemeyer J et al (2009). The adenosine A2A antagonist MSX-3 reverses the effects of the dopamine antagonist haloperidol on effort-related decision making in a T-maze cost-benefit procedure. Psychopharmacology 204: 103-112.

Nierenberg AA, Husain MM, Trivedi MH, Fava M, Warden D, Wisniewski SR et al (2010). Residual symptoms after remission of major depressive disorder with citalopram and risk of relapse: a $\mathrm{STAR}^{\star} \mathrm{D}$ report. Psychol Med 40: 41-50.

Nunes EJ, Randall PA, Hart EE, Freeland C, Yohn SE, Baqi Y et al (2013). Effort-related motivational effects of the VMAT-2 inhibitor tetrabenazine: implications for animal models of the motivational symptoms of depression. J Neurosci 33: 19120-19130.

Nunes EJ, Randall PA, Estrada A, Epling B, Hart EE, Lee CA et al (2014). Effort-related motivational effects of the proinflammatory cytokine interleukin 1-beta: studies with the concurrent fixed ratio 5/chow feeding choice task. Psychopharmacology 231: 727-736.

Nutt D, Demyttenaere K, Janka Z, Aarre T, Bourin M, Canonico PL et al (2007). The other face of depression, reduced positive affect: the role of catecholamines in causation and cure. J Psychopharmacol 21: 461-471.

Padala PR, Padala KP, Monga V, Ramirez DA, Sullivan DH (2012). Reversal of SSRI-associated apathy syndrome by discontinuation of therapy. Ann Pharmacother 46: e8.

Papakostas GI, Nutt DJ, Hallet LA, Tucker VL, Krishen A, Fava M (2006). Resolution of sleepiness and fatigue in major depressive disorder: a comparison of bupropion and the selective serotonin reuptake inhibitors. Biol Psychiatry 15: 1350-1355.

Pardo M, López-Crus L, Miguel NS, Salamone JD, Correa M (2015). Selection of sucrose concentration depends on the effort required to obtain it: studies using tetrabenazine, D1, D2, D3 receptor antagonists. Psychopharmacology 232: 2377-2391.

Podurgiel SJ, Milligan MN, Yohn SE, Purcell LJ, Contreras-Mora HM, Correa $\mathrm{M}$ et al (2015). Fluoxetine administration exacerbates oral tremor and striatal dopamine depletion in a rodent pharmacological model of parkinsonism. Neuropsychopharmacology 40: 2240-2247.

Pizzagalli DA (2014). Depression, stress, and anhedonia: toward a synthesis and integrated model. Annu Rev Clin Psychol 10: 393-423.

Randall PA, Pardo M, Nunes EJ, López Cruz L, Vemuri VK, Makriyannis A et al (2012). Dopaminergic modulation of effort- related choice behavior as assessed by a progressive ratio chow feeding choice task: pharmacological studies and the role of individual differences. PLoS One 7: e47934.

Randall PA, Lee CA, Nunes EJ, Yohn SE, Nowak V, Khan B et al (2014). The VMAT-2 inhibitor tetrabenazine affects effort-related decision making in a progressive ratio/chow feeding choice task: reversal with antidepressant drugs. PLoS One 9: e99320.

Randall PA, Lee CA, Podurgiel SJ, Hart E, Yohn SE, Jones M et al (2015). Bupropion increases selection of high effort activity in rats tested on a progressive ratio/chow feeding choice procedure: implications for treatment of effort-related motivational symptoms. Int J Neuropsychopharmacol 18: 1-11.

Robbins TW, Everitt BJ (2007). The role for mesencephalic dopamine in activation: commentary on Berridge. Psychopharmacology (Berl) 191: 433-437.

Rothschild AJ, Raskin J, Wang CN, Marangell LB, Fava M (2014). The relationship between change in apathy and changes in cognition and functional outcomes in currently non-depressed SSRI-treated patients with major depressive disorder. Compr Psychiatry 55: 1-10.

Salamone JD, Correa M (2002). Motivational views of reinforcement: implications for understanding the behavioral functions of nucleus accumbens dopamine. Behav Brain Res 137: 3-25.

Salamone JD, Correa M (2012). The mysterious motivational functions of mesolimbic dopamine. Neuron 76: 470-485.

Salamone JD, Correa M, Mingote S, Weber SM (2003). Nucleus accumbens dopamine and the regulation of effort in food-seeking behavior: implications for studies of natural motivation, psychiatry, and drug abuse. J Pharmacol Exp Ther 305: 1-8.

Salamone JD, Correa M, Farrar A, Mingote SM (2007). Effortrelated functions of nucleus accumbens dopamine and associated forebrain circuits. Psychopharmacology 191: 461-482.

Sanders AC, Hussain AJ, Hen R, Zhuang X (2007). Chronic blockade or constitutive deletion of the serotonin transporter reduces operant responding for food reward. Neuropsychopharmacology 32: 2321-2329.

Schweimer J, Saft S, Hauber W (2005). Involvement of catecholamine neurotransmission in the rat anterior cingulate in effortrelated decision making. Behav Neurosci 119: 1687-1692.

Schweimer J, Hauber W (2006). Dopamine D1 receptors in the anterior cingulate cortex regulate effort-related decision making. Learn Mem 13: 777-782.

Shafiei N, Gray M, Viau V, Floresco SB (2012). Acute stress induces selective alterations in cost/benefit decision-making. Neuropsychopharmacology 37: 2194-2209.

Sink KS, Vemuri VK, Olszewska T, Makriyannis A, Salamone JD (2008). Cannabinoid CB1 antagonists and dopamine antagonists produce different effects on a task involving response allocation and effort-related choice in food-seeking behavior. Psychopharmacology 196: 565-574.

Stahl SM (2002). The psychopharmacology of energy and fatigue. $J$ Clin Psychiatry 63: 7-8.

Stotz G, Woggon B, Angst J (1998). Psychostimulants in the therapy of treatment-resistant depression. Dialogues Clin Neurosci 1: 165-174.

Stenman E, Lilja A (2013). Increased monoaminergic neurotransmission improves compliance with physical activity recommendations in depressed patients with fatigue. Med Hypotheses 80: 47-49.

Tadano T, Nakagawasai O, Jiijima F, Tan-No K, Kisara K (2000). The effects of traditional tonics on fatigue in mice differ from those of the antidepressant imipramine: a pharmacological and behavioral study. Am J Chin Med 28: 97-104.

Treadway MT, Zald DH (2011). Reconsidering anhedonia in depression: lessons from translational neuroscience. Neurosci Biobehav Rev 35: 537-555.

Treadway MT, Bossaller NA, Shelton RC, Zald DH (2012). Effortbased decision-making in major depressive disorder: a translational model of motivational anhedonia. J Abnorm Psychol 121: 553-558. 
Tylee A, Gastpar M, Lépine JP, Mendlewicz J (1999). Identification of depressed patient types in the community and their treatment needs: findings from the DEPRES II (Depression Research in European Society II) survey. Int Clin Psychopharmacol 14: 153-165.

Wang H, Chen X, Li Y, Tang TS, Bezprozvanny I (2010). Tetrabenazine is neuroprotective in Huntington's disease mice. Mol Neurodegener 5: 18.

Yamada J, Sugimoto Y, Yamada S (2004). Involvement of dopamine receptors in the anti-immobility effects of dopamine re-uptake

inhibitors in the forced swimming test. Eur J Pharmacol 504: 207-211.

Yohn SE, Thompson C, Randall PA, Lee CA, Müller CE, Bagi Y et al (2015). The VMAT-2 inhibitor tetrabenazine alters effort-related decision making as measured by the T-maze barrier choice task: reversal with the adenosine A2A antagonist MSX-3 and the catecholamine uptake blocker bupropion. Psychopharmacology 232: 1313-1323. 